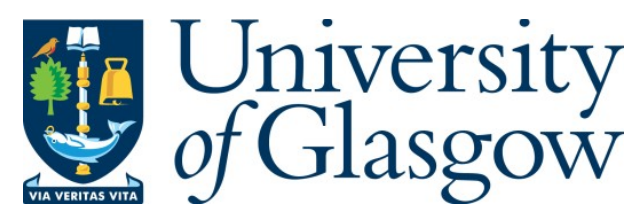

Kinsella, J., Hawthorne, C., Shaw, M., Piper, I., Elliott, R., Lee, C., and Moss, L. (2016) Public perception of the collection and use of critical care patient data beyond treatment: a pilot study. Critical Care Medicine, 44(12 S1), p. 470.

There may be differences between this version and the published version. You are advised to consult the publisher's version if you wish to cite from it.

http://eprints.gla.ac.uk/132284/

Deposited on: 5 December 2016

Enlighten - Research publications by members of the University of Glasgow http://eprints.gla.ac.uk 


\title{
Public Perception of the Collection and Use of Critical Care Patient Data Beyond Treatment: a Pilot Study
}

\author{
John Kinsella ${ }^{1}$, Christopher Hawthorne ${ }^{3}$, Martin Shaw ${ }^{2}$, Ian Piper ${ }^{2}$, Richard Elliott ${ }^{3}$, Christine Lee $^{4}$, Laura Moss ${ }^{1,2}$ \\ ${ }^{1}$ Dept. of Anaesthesia, Pain \& Critical Care, University of Glasgow, Glasgow, UK \\ ${ }^{2}$ Dept. of Clinical Physics \& Bioengineering, Institute of Neurological Sciences, NHS Greater Glasgow \& Clyde, \\ Glasgow, UK \\ ${ }^{3}$ Dept. of Neuroanaesthesia, Institute of Neurological Sciences, NHS Greater Glasgow \& Clyde, Glasgow, UK \\ ${ }^{3}$ Philips Healthcare UK \\ ${ }^{4}$ Aridhia Ltd
}

\section{Background}

Technology has transformed critical care medicine and increasingly leads to the development of large databases of patient information. There is public interest in use of this data; it is a valuable source which can drive clinical research and lead to improved patient treatment, but concerns are voiced about the security and privacy of this data. We describe a survey which asked the general public at a science festival about this topic.

\section{Methods}

We asked the following: if participants were aware of the potential of medical data for research purposes; previous involvement in clinical research; their use of social media; whether data should be used for research purposes and how likely would they be to share their own personal data for research; if they trust clinicians with their data; and their opinions on the role of private companies in supporting and/or carrying out research on their medical data.

\section{Results}

39 out of 41 adults responded to the survey. 32 (82.1\%) were aware that medical data could be used for research. 31 (79.5\%) regularly use social media, of these only $1(2.56 \%)$ shared health information on it. 34 $(87.2 \%)$ strongly agreed/agreed that medical data should be used for research whilst 4 (10.3\%) were undecided. 32 (82.1\%) strongly agreed/agreed they were happy to share their medical data, 4 (10.3\%) were undecided and 2 (5.1\%) disagreed/strongly disagreed. 27 (69.2\%) strongly agreed/agreed that they trusted clinicians with their medical data, 7 (17\%) were undecided and $3(7.7 \%)$ disagreed/strongly disagreed. Whereas, $8(20.5 \%)$ strongly agreed/agreed that they trusted private companies to use medical data for research purposes, 20 (51.28\%) were undecided and 9 (23.1\%) disagreed/strongly disagreed.

\section{Conclusions}

Response to the use of medical data for research purposes is positive; a majority supported and trusted clinicians. This was not as strongly observed when private companies were involved; this has implications for healthcare providers, policy makers and researchers. This study will be followed up with a more extensive survey. 